\title{
Assessment of safety and efficacy of oral nifedipine and intravenous labetalol in management of increased blood pressure in severe preeclampsia
}

\author{
Sujana Thalamati, Sailaja Bandaru*, Divyasree Bhumireddy
}

Department of Obstetrics and Gynecology, Narayana Medical College, Nellore, Andhra Pradesh, India

Received: 29 May 2018

Accepted: 02 June 2018

*Correspondence:

Dr. Sailaja Bandaru,

E-mail: sujatha2481@gmail.com

Copyright: () the author(s), publisher and licensee Medip Academy. This is an open-access article distributed under the terms of the Creative Commons Attribution Non-Commercial License, which permits unrestricted non-commercial use, distribution, and reproduction in any medium, provided the original work is properly cited.

\begin{abstract}
Background: Pre-eclampsia (PE) is a disorder of pregnancy characterized by the onset of high blood pressure and often a significant amount of protein in the urine. Pre-eclampsia is one of the leading causes of maternal and perinatal morbidity and mortality worldwide. The objective of the present study was to assess and compare the safety and efficacy of oral nifedipine and intravenous labetalol in the management of severe pre-eclampsia.

Methods: A double-blind, randomized, controlled trial was conducted at a tertiary care hospital in Andhra Pradesh, on pregnant women presenting with a systolic blood pressure of $160 \mathrm{~mm} \mathrm{Hg}$ or more or diastolic blood pressure of $110 \mathrm{~mm} \mathrm{Hg}$ or more. The pregnant women were randomized to receive Oral nifedipine (10 $\mathrm{mg}$ tablet orally up to five doses) and intravenous labetalol injection in escalating doses until the target blood pressure of $150 \mathrm{~mm} \mathrm{Hg}$ systolic and $100 \mathrm{~mm} \mathrm{Hg}$ diastolic, or lower, was achieved. The primary endpoint of the study was the time taken by each agent to achieve target blood pressure. Secondary endpoints were number of doses required, adverse maternal and neonatal effects, side effect profile, and perinatal outcome.

Results: The study was conducted in a tertiary care hospital in Andhra Pradesh from July 2016 to October 2017, on 100 pregnant women presenting with preeclampsia. The median time taken to achieve target blood pressure was 44 minutes (range: 20-60 minutes) for Oral Nifedipine and 68 minutes (range: 40-85 minutes) for Intravenous labetalol $(\mathrm{P}=0.008)$. No serious adverse maternal or perinatal side effects were encountered in both the groups.

Conclusions: Both oral nifedipine and intravenous labetalol are effective in the management of acute hypertensive emergencies of pregnancy; however, oral nifedipine effectively decreased the blood pressure rapidly compared to intravenous labetalol.
\end{abstract}

Keywords: Blood pressure, Labetalol, Nifedipine, Preeclampsia

\section{INTRODUCTION}

Pre-eclampsia (PE) is a disorder of pregnancy characterized by the onset of high blood pressure and often a significant amount of protein in the urine. Preeclampsia is one of the leading causes of maternal and perinatal morbidity and mortality worldwide. Preeclampsia affects approximately $2-8 \%$ of all pregnancies worldwide. ${ }^{1-3}$ The condition begins after 20 weeks of pregnancy but more common after 32 weeks of Gestation. ${ }^{4,5}$ Nearly one-tenth of all maternal deaths in Africa and Asia and one-quarter in Latin America are associated with hypertensive diseases in pregnancy, a category that encompasses pre-eclampsia. ${ }^{6}$ Severe preeclampsia is characterized by systolic blood pressure $\geq 160 \mathrm{mmHg}$ and diastolic blood pressure of $\geq 110 \mathrm{mmHg}$. In severe disease there may be red blood cell breakdown, a low blood platelet count, impaired liver function, 
kidney dysfunction, swelling, shortness of breath due to fluid in the lungs, or visual disturbances. Severe preeclampsia requires prompt and effective treatment to prevent cerebrovascular and cardiovascular complications such as hypertensive encephalopathy, intracerebral haemorrhage and pulmonary oedema. ${ }^{7}$ It also presents an increased risk of complications for the foetus including prematurity, low birth weight, NICU admissions and eventually foetal death. While historically both high blood pressure and protein in the urine were required to make the diagnosis, some definitions also include those with hypertension and any associated organ dysfunction. Blood pressure is defined as high when it is greater than $140 \mathrm{mmHg}$ systolic or $90 \mathrm{mmHg}$ diastolic at two separate times, more than four hours apart in a woman after twenty weeks of pregnancy.

Antihypertensive treatment should be started in women with severe hypertension $\geq 160 / 110 \mathrm{mmHg}$ to reduce the blood pressure between $140-155 \mathrm{mmHg}$ systolic and 90 $100 \mathrm{mmHg}$ diastolic. Care should be taken not to lower the blood pressure too rapidly so as to avoid reduced renal and placental perfusion and intrauterine hypoxia leading to sudden foetal death. The most commonly used antihypertensive drugs for control of severe hypertension in pre-eclampsia are nifedipine, labetalol and hydralazine.

Nifedipine has the advantage of being cost effective, rapid onset of action, long duration of action, oral bioavailability, easier to store and infrequent side effects. Intravenous labetalol is effective in controlling severe hypertension and can be given even when the patient is unconscious but is expensive. A recent meta-analysis demonstrated that IV hydralazine for the control of severe hypertension in pregnancy was associated with significant maternal hypotension, placental abruption, maternal oliguria and adverse effect on foetal heart rate. ${ }^{8}$ They conclude that they do not support the use of hydralazine as the first line treatment. A safe and efficient drug is the need of the hour amongst the two most commonly used drugs, i.e. oral nifedipine and IV labetalol. Hence the present study was undertaken to assess and compare the safety and efficacy of oral nifedipine and intravenous labetalol in the management of Severe Preeclampsia.

\section{METHODS}

This prospective randomized controlled trial was conducted in the Department of Obstetrics and Gynaecology, Narayana Medical College, Nellore, a tertiary care hospital in Andhra Pradesh, from July 2016 to December 2017. Institutional ethical committee clearance was obtained before starting this study. A written informed consent was taken from all the study participants.

Pregnant women at $\geq 20$ weeks of gestation attending the OPD and Labour ward, with sustained severe hypertension $\geq 160 \mathrm{mmHg}$ systolic and $\geq 110 \mathrm{mmHg}$ diastolic blood pressure. Pregnant women suffering from Chronic Hypertension, Cardiac disease, Bronchial Asthma were excluded from the study. Assignment of the participants was done alternately, to either Nifedipine group or Labetalol group. Regular Blood pressure measurements were done for every 3 minutes, after the administration of the drugs. Nifedipine $10 \mathrm{mg}$ oral dose and dose escalation of Labetalol in the regimen of $20 \mathrm{mg}$, $40 \mathrm{mg}, 80 \mathrm{mg}, 80 \mathrm{mg}$ and $80 \mathrm{mg}$ was done every 15 minutes. If Target blood pressure was not achieved, even after 5 administrations, a crossover of the regimen was planned.

The time required for blood pressure to reach the target value was noted. The number of doses required to achieve the target value was noted. Adverse effects like nausea, vomiting, dizziness, palpitations, chest pain, sweating and shortness of breath if any were noted.

The mode of delivery, maternal and perinatal morbidity and mortality were noted. The neonates if admitted in NICU were followed up till discharge.

\section{RESULTS}

Age distribution in the study group, has shown that the mean age of labetalol group was $23 \pm 5$ years and $24 \pm 4$ years in nifedipine group (Table 1).

Table 1: Age distribution of cases in the study.

\begin{tabular}{|lll|} 
Age group & $\begin{array}{l}\text { Oral nifedipine } \\
(\mathbf{N}=50)\end{array}$ & IV labetalol(N=50) \\
\hline $18-20$ & $13(26 \%)$ & $10(20 \%)$ \\
$21-25$ & $23(46 \%)$ & $24(48 \%)$ \\
\hline $26-30$ & $10(20 \%)$ & $11(22 \%)$ \\
\hline $31-40$ & $4(8 \%)$ & $5(10 \%)$ \\
\hline
\end{tabular}

Gravida distribution shows maximum patients of preeclampsia were primigravida in both the groups $(62 \%$ in the labetalol and $52 \%$ in the nifedipine group (Table 2).

Table 2: Distribution by parity of cases in the study.

\begin{tabular}{|lll|}
\hline Gravida & $\begin{array}{l}\text { Oral Nifedipine } \\
(\mathbf{N}=50)\end{array}$ & $($ IV) Labetalol $(\mathrm{N}=50)$ \\
\hline Primi & $29(58 \%)$ & $25(50 \%)$ \\
\hline G2 & $12(24 \%)$ & $15(30 \%)$ \\
\hline G3 & $5(10 \%)$ & $8(16 \%)$ \\
G4 & $4(8 \%)$ & $2(4 \%)$ \\
\hline
\end{tabular}

Most patients with preeclampsia were at 33-36 weeks. gestational age $(58 \%$ in labetalol and $62 \%$ in nifedipine group). Minimum gestational age at presentation was 27 weeks and 28 weeks. in labetalol and nifedipine group respectively (Table 3 ).

The systolic blood pressure on the day of admission was $160 \mathrm{mmHg}$ in $38 \%$ of labetalol group and $40 \%$ of nifedipine group, $200 \mathrm{mmHg}$ in $2 \%$ of labetalol and 
nifedipine groups each. The mean systolic blood pressure on the day of admission was $174 \mathrm{mmHg}$ in labetalol group and $173 \mathrm{mmHg}$ in nifedipine group ( $\mathrm{p}$ value 0.87 not significant). The mean diastolic blood pressure on the day of admission was $114 \mathrm{mmHg}$ in labetalol group and $115 \mathrm{mmHg}$ in nifedipine group ( $\mathrm{p}$ value 0.72 not significant).

Table 3: Gestational age distribution.

\begin{tabular}{|lll|}
\begin{tabular}{|l} 
Gestational \\
age
\end{tabular} & $\begin{array}{l}\text { Oral Nifedipine } \\
(\mathbf{N}=50)\end{array}$ & $\begin{array}{l}(\mathrm{IV}) \text { Labetalol } \\
(\mathbf{N}=50)\end{array}$ \\
\hline $26-28$ & $1(2 \%)$ & $1(2 \%)$ \\
\hline $29-32$ & $12(24 \%)$ & $9(18 \%)$ \\
\hline $33-36$ & $27(54 \%)$ & $32(64 \%)$ \\
\hline $37-39$ & $10(20 \%)$ & $8(16 \%)$ \\
\hline
\end{tabular}

The minimum time to achieve target B.P was $10 \mathrm{~min}$. in both the groups. The mean time taken to achieve the target B.P $36.61 \pm 5.2 \mathrm{~min}$ in labetalol group and $34.77 \pm 4.8 \mathrm{~min}$ in nifedipine group ( $\mathrm{p}$ value was 0.29 which was not significant statistically). The target B.P was achieved within $80 \mathrm{~min}$ in both groups (Table 4).

Table 4: Mean time taken to achieve target blood pressure.

\begin{tabular}{|l|l|}
\hline Drug & Time (Minutes) \\
\hline Oral Nifedipine & $34.77 \pm 4.8$ \\
\hline Iv labetalol & $36.61 \pm 5.2$ \\
\hline
\end{tabular}

On an average the labetalol group needed three doses and the nifedipine group required two doses to control the B.P to target level. The $p$ value of 0.43 indicates that there was no significant difference in the number of dose required to achieve the desired B.P. There was no indication for crossover treatment.

The various side effects of the drugs like dizziness, sweating, nausea, vomiting, palpitations, headache and shortness of breath showed no statistical significance among the two drugs. Maternal hypotension or foetal tachycardia was not seen in either of the study groups (Table 5).

Table 5: Distribution of adverse effects.

\begin{tabular}{|llll|}
\hline Adverse effect & $\begin{array}{l}\text { Oral } \\
\text { nifedipine } \\
(\mathbf{N}=50)\end{array}$ & $\begin{array}{l}\text { Iv } \\
\text { labetalol } \\
(\mathbf{N}=50)\end{array}$ & $\begin{array}{l}\text { p- } \\
\text { value }\end{array}$ \\
\hline Hypotension & 0 & 0 & 0 \\
\hline Dizziness & $2(4 \%)$ & $3(6 \%)$ & 0.15 \\
\hline Flushing & $1(2 \%)$ & $1(2 \%)$ & 0 \\
\hline Nausea/Vomiting & $2(4 \%)$ & $4(8 \%)$ & 0.23 \\
\hline Palpitation & $3(6 \%)$ & $5(10 \%)$ & 0.29 \\
\hline Headache & $4(8 \%)$ & $6(12 \%)$ & 0.34 \\
\hline Breathlessness & $2(4 \%)$ & $2(4 \%)$ & NS \\
\hline Foetal distress & 0 & 0 & 0 \\
\hline
\end{tabular}

Regarding mode of delivery in nifedipine group there were 22 caesarean sections and 28 vaginal deliveries. In labetalol group there were 24 caesarean sections and 26 vaginal deliveries. $p$ value 0.25 did not reveal any statistical significance.

The average birth weight of babies in nifedipine group was $2.41 \mathrm{~kg}$ and for the labetalol group was $2.38 \mathrm{~kg}$. p value was 0.72 which was not statistically significant.

The Apgar score of $<7$ at 5 minutes was seen in $10 \%$ of the labetalol group and $12 \%$ of the nifedipine group.

$90 \%$ of the labetalol group and $88 \%$ of the nifedipine group showed APGAR score of $\geq 7$ at 5 minutes. $p$ value of 0.67 was not significant statistically.

The neonatal complications like prematurity, NICU admissions, respiratory distress hyperbilirubinemia was comparable among the two groups

There were 2 IUD's and 2 neonatal deaths among the labetalol group and 2 IUD's and 3 neonatal deaths in the nifedipine group. The $\mathrm{p}$ value was not statistically significant.

\section{DISCUSSION}

This randomized controlled study compares the efficacy of two antihypertensive drugs, oral nifedipine and I. V. Labetalol. 100 patients were included in the trial of which 50 were randomized to nifedipine and another 50 were randomized to labetalol group.

All the patients were aged between 18-40 years. Mean age in the labetalol group was $23 \pm 5$ and $24 \pm 4$ in the nifedipine group comparable to the study conducted by Dhali B et al. ${ }^{9}$ With regard to gravida distribution maximum patients of pre-eclampsia were primigravida in both the groups, 62\% in the labetalol and 52\% in nifedipine group comparable with the study of Shekar et al and Raheem et al. ${ }^{10,11}$

In the present study most of the patients with preeclampsia were between 33-36 weeks of gestation, $58 \%$ in labetalol and $62 \%$ in nifedipine group. Mean gestational age in labetalol group is $35.4 \pm 2.12$ weeks and in nifedipine group $35.3 \pm 2.3$ weeks. In a study conducted by Sekhar et al mean gestational age was $36.1 \pm 3.2$ weeks in labetalol group and $37.3 \pm 2.12$ weeks in nifedipine group. ${ }^{10}$ In present study the mean systolic blood pressure in labetalol group was $174 \mathrm{mmHg}$ and in nifedipine group it was $173 \mathrm{mmHg}$. ' $\mathrm{P}$ ' value was 0.87 which is not significant. In the study conducted by Raheem et al the systolic blood pressure was $170 \mathrm{mmHg}$ in labetalol group and $175 \mathrm{mmHg}$ in nifedipine group. In the present study the mean diastolic blood pressure in labetalol group was $114 \mathrm{mmHg}$ and in nifedipine group it was 115 . p value was 0.7 which is not significant. In the study of Raheem 
et al the mean diastolic blood pressure was $108 \mathrm{mmHg}$ in labetalol group and $110 \mathrm{mmHg}$ in nifedipine group.

In the present study the mean time taken to achieve target blood pressure in labetalol group is $36.61 \pm 5.2$ minutes and in nifedipine group it is $34.77 \pm 4.8$ minutes. $\mathrm{p}$ value was 0.29 which is not statistically significant. Many studies have shown that both labetalol and nifedipine can be used successfully in treating hypertensive crisis in pregnancy. In the study conducted by Raheem et al on the same drugs in pregnancy the median time taken by the labetalol group to achieve target blood pressure was 45 minutes and by the nifedipine group was 30 minutes which was comparably low when compared to present study.

The Trial conducted by Vermillion et al indicated that patients receiving oral nifedipine more rapidly achieved therapeutic blood pressure goal in $25.0 \pm 13.6$ minutes as compared with $43.6 \pm 25.4$ minutes in women receiving intravenous labetalol $(\mathrm{P}=0.002) .{ }^{12}$ Vermillion drug regimen used higher oral nifedipine doses i.e. $10 \mathrm{mg}$ initially, then $20 \mathrm{mg}$ for further doses as required. Authors used $10 \mathrm{mg}$ nifedipine throughout. Intravenous labetalol dose used was 20,40,80,80 and $80 \mathrm{mg}$ in their study which is identical to the dose of labetalol used in present study.

In present study nifedipine group required 2 doses to reduce the blood pressure and labetalol group required 3 doses to achieve the same effect keeping with the findings of Raheem et al. In present study none of the individuals required crossover treatment. In the study conducted by Raheem et al $20 \%$ of labetalol group and $20 \%$ of nifedipine group required crossover treatment. Regarding the side effects of the two drugs there was no incidence of maternal hypotension or foetal tachycardia in both the groups. Other side effects were of minor degree and are comparable with other studies. In present study the mean birth weight was $2.28 \pm 0.5$ in labetalol group and $2.31 \pm 0.24$ in nifedipine group which is comparable with the study of Shekar et al where the mean birth weight in labetalol group was $2.2 \pm 0.60 \mathrm{~kg}$ and $2.4 \pm 0.50 \mathrm{~kg}$ in nifedipine group. ${ }^{10}$

Cochrane review of 2006 has concluded that there is no clear evidence that one antihypertensive is preferable to the other for improving outcome for women with very high blood pressure during pregnancy. Until better evidence is available the best choice of drug for an individual woman probably depends on the experience and familiarity with a particular drug and its maternal and foetal side effects. ${ }^{13}$

Present study indicates that both oral nifedipine and intravenous labetalol regimens are effective in controlling severe hypertension in pregnancy. There were no major side effects attributable to either drug regimens. Present study is in accordance with the guidelines and expert opinion that oral nifedipine and intravenous labetalol can be used as first line antihypertensive drugs for control of severe hypertension in pregnancy. ${ }^{14,15}$

\section{CONCLUSION}

In the present study, oral nifedipine was more effective compared to IV labetalol in the control of hypertension in severe preeclampsia. Both drugs demonstrated a similar adverse effects profile. Nifedipine is easier to store, easier to administer as it is given orally whereas IV labetalol is more expensive, needs to be stored at a lower temperature and needs slower administration. Thus, the present study concludes that both oral nifedipine is more effective compared to IV labetalol in acute control of blood pressure in severe preeclampsia and the treatment is also cost effective whereas Inj. labetalol can be reserved for unconscious or drowsy individuals.

\section{Funding: No funding sources \\ Conflict of interest: None declared}

Ethical approval: The study was approved by the Institutional Ethics Committee

\section{REFERENCES}

1. Eiland E, Nzerue C, Faulkner M. Preeclampsia 2012. J Preg. 2012:1-7.

2. Hypertension in pregnancy. Am Coll Oobstet Gynecol. 2013:2.

3. Al-Jameil N, Khan FA, Khan MF, Tabassum H. A brief overview of preeclampsia. J Clin Med Res. 2014;6(1):1.

4. American College of Obstetricians and Gynecologists. Hypertension in pregnancy. Report of the American College of Obstetricians and Gynecologists' task force on hypertension in pregnancy. Obstetrics and gynecology. 2013;122(5):1122.

5. Berg CJ, Chang J, Callaghan WM, Whitehead SJ. Pregnancy-related mortality in the united states 1991-1998. Obstet Gynecol. 2003;101(2):289-96.

6. WHO recommendations for prevention and treatment of pre-eclampsia and eclampsia. 2011.

7. National Institute of Health and Clinical Excellence. Hypertension in pregnancy: the management of hypertensive disorders during pregnancy.NICE clinical guidelines 107. 2010. Available from www.nice.org.uk/niemedia/live/13098/50418.

8. Magee LA, Cham C, Waterman EJ, Ohlsson A, Von Dadelszen P. Hydralazine for treatment of severe hypertension in pregnancy: meta-analysis. Br Med J. 2003;327(7421):955.

9. Dhali B, Bhattacharya S, Ganguly RP, Bandyopadhyay S, Mondal M, Dutta M. A randomized trial of intravenous labetalol \& oral nifedipine in severe pregnancy induced hypertension. Int J Reprod Contracept Obstet Gynecol. 2016;1(1):42-6.

10. Shekhar S, Sharma C, Thakur S, Verma S. Oral nifedipine or intravenous labetalol for hypertensive 
emergency in pregnancy: a randomized controlled trial. Obstet Gynecol. 2013;122(5):1057-63.

11. Raheem IA, Saaid R, Omar SZ, Tan PC. Oral nifedipine versus intravenous labetalol for acute blood pressure control in hypertensive emergencies of pregnancy: a randomised trial. BJOG: An Int J Obstet Gynaecol. 2012;119(1):78-85.

12. Vermillion ST, Scardo JA, Newman RB, Chauhan SP. A randomized, double-blind trial of oral nifedipine and intravenous labetalol in hypertensive emergencies of pregnancy. Am J Obstet Gynecol. 1999;181(4):858-61.

13. Duely L, Henderson-Smart DJ, Meher S. Drugs for treatment of very high blood pressure during pregnancy. Cochrane Database Syst Rev 2006;47:279-85.
14. The Royal College of Obstetricians and Gynaecologists, United Kingdom. Green top guideline No 10(A). The management of severe preeclampsia/eclampsia.2006. Accessible online www.rcog.org.uk/files/GT10a ManagementPreeclampsia2006.pdf

15. Sibai BM. Diagnosis and management of gestational hypertension and preeclampsia. Obstet Gynecol. 2003;102(1):181-92.

Cite this article as: Thalamati $\mathrm{S}$, Bandaru $\mathrm{S}$, Bhumireddy D. Assessment of safety and efficacy of oral nifedipine and intravenous labetalol in management of increased blood pressure in severe preeclampsia. Int J Reprod Contracept Obstet Gynecol 2018;7:2645-9. 